Ihab Kaddoura, Lars Kröger, Kai Nagel

\title{
An activity-based and dynamic approach to calculate road traffic noise damages
}

Journal article | Submitted manuscript (Preprint)

This version is available at https://doi.org/10.14279/depositonce-7725

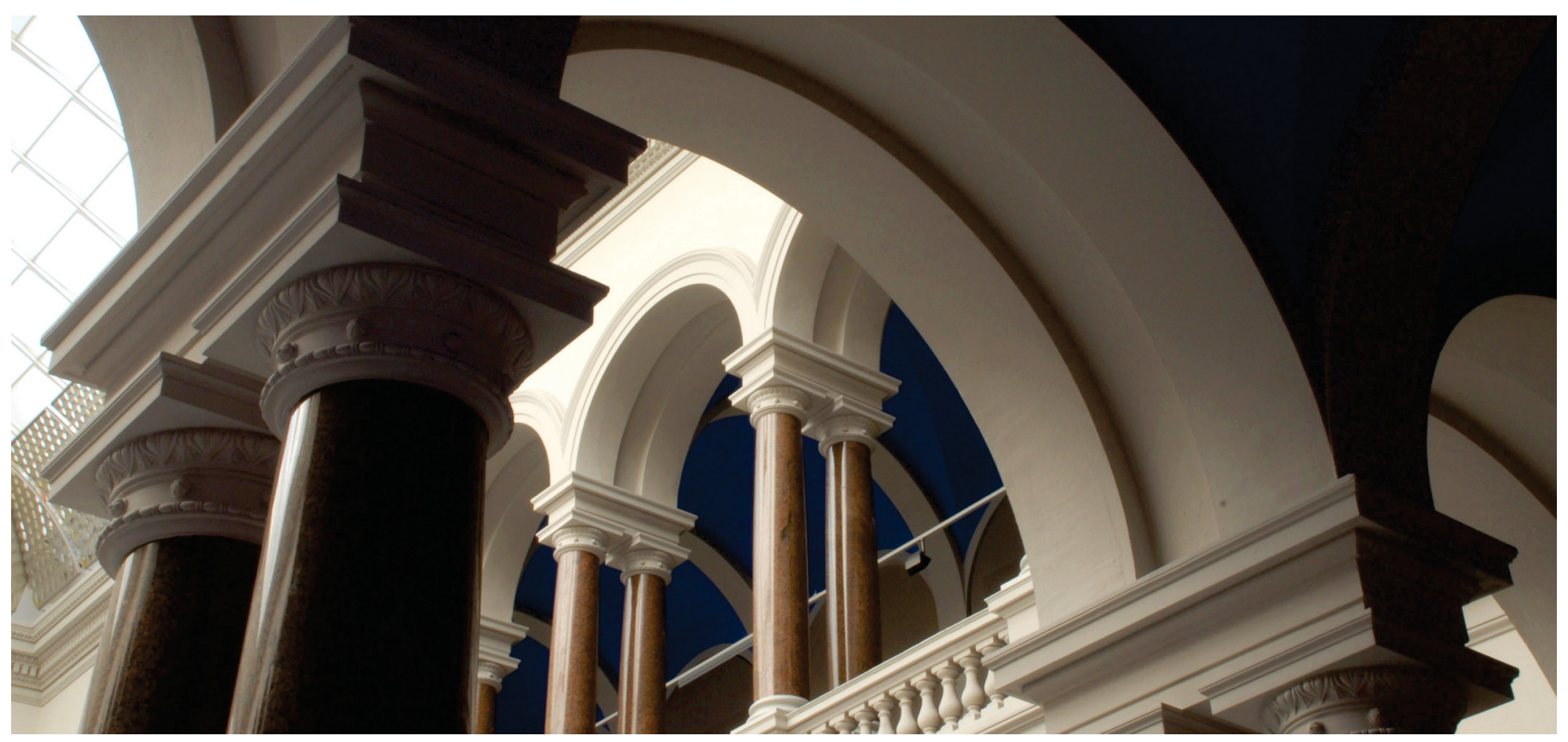

Kaddoura, I., Kröger, L., \& Nagel, K. (2017). An activity-based and dynamic approach to calculate road traffic noise damages. Transportation Research Part D: Transport and Environment, 54, 335-347. https://doi.org/10.1016/j.trd.2017.06.005 


\title{
An activity-based and dynamic approach to calculate road traffic noise damages
}

\author{
Ihab Kaddoura*, Lars Kröger, Kai Nagel \\ Technische Universität Berlin \\ Department of Transportation System Planning and Telematics \\ Salzufer 17-19; 10587 Berlin; Germany \\ * Corresponding author (e-mail: kaddoura@vsp.tu-berlin.de)
}

February 12, 2015

\begin{abstract}
In this paper, an activity-based and dynamic approach is presented to analyze population exposures to road traffic noise. The contribution of this innovative approach is that (1) affected people at the workplace and places of education are incorporated and (2) the within day dynamics of varying population densities in different areas of the city is explicitly taken into account. The proposed methodology is applied to a real-world case study of the Greater Berlin area. The results demonstrate the need to account for the spatial and temporal variation in the population since the use of static resident numbers would result in an overestimation of residential noise damages. Going beyond residential exposures, the inclusion of further activity types is found to have a substantial effect on the results. Assuming individuals at work or education to be additionally affected by noise, population exposures in the central business districts are much larger than in residential areas. The proposed approach may be seen as a first step towards improved noise mapping standards to provide better recommendations for policy makers and ensure a more efficient use of noise control strategies.
\end{abstract}

Keywords: Road Traffic Noise, Exposure Analysis, Noise Maps, Activity-based Transport Modeling, END 2002/49/EC 


\section{Introduction and problem statement}

Environmental noise is described as a growing public health problem (WHO Europe, 2011) and to cause sleep disturbance, cognitive impairment, tinnitus and cardiovascular diseases (see, e.g., Ising et al., 1996; Stassen et al., 2008; WHO Europe, 2009, 2011; Babisch et al., 2013). A recent survey reveals that more than half of the population in Germany feels annoyed or disturbed by road traffic noise (Rückert-John et al., 2013). The Environmental Noise Directive of the European Union 2002/49/EC aims to reduce these effects. In order to identify priorities for action planning, an approach is defined to draw up strategic noise maps based on national computation methods and a standardized noise indicator (2002/49/EC, App. 1 and 2). ${ }^{1}$ Several noise computation models have been developed in different countries, e.g. the RLS-90 (Richtlinien für den Lärmschutz an Straßen) in Germany (FGSV, 1992), the CoRTN (Calculation of Road Traffic Noise) in the United Kingdom (Department of Transport, 1988), the Nordic Prediction Method in Norway, Denmark, Sweden and Finland (Nielsen et al., 1996). In a recent study by Garg and Maji (2014) a comparative review of the different calculation approaches is provided.

For the prioritization of noise control measures the computation of noise exposures to individuals is a crucial element. According to App. 4 of 2002/49/EC strategic noise mapping may include the presentation of a noise indicator or the exceeding of limit values, but also of estimates for the number of people or certain buildings that are exposed to noise. Eriksson et al. (2013) compare predicted and survey-based exposures and find Swedish noise maps to be useful for the assessment of residential traffic noise exposures. To indicate the exposures to the population, most noise maps include the building boundaries, however, the number of people that is exposed to certain noise levels is usually not directly shown in the map (see, e.g., SenStadt (2012b) for Berlin and DEFRA (2014) for London). Tables or charts may additionally provide estimates for the population exposures, however, theses numbers are usually spatially aggregated at city or post code level (see, e.g. SenStadt, 2012a; DEFRA, 2015).

Since certain buildings, i.e. schools and hospitals, are explicitly mentioned in 2002/49/EC, noise exposure analysis is not limited to residents at their home location. However, the

\footnotetext{
${ }^{1}$ For an implementation of 2002/49/EC at national level, see, e.g. 34. BImSchV for Germany or 2006 No. 2238 for England.
} 
data to be sent to the European Commission specified in App. 6 of 2002/49/EC only refers to residential noise exposures. Moreover, also the 'Good Practice Guide for Strategic Noise mapping and the Production of Associated Data on Noise Exposures' which provides recommendations regarding the computation of sound sources, noise propagation and noise immission at the receiver point, only refers to people that are affected in dwellings (WGAEN, 2006). As a consequence, noise exposure analysis usually follows a home-based approach by estimating the number of people living in each building (see, e.g. SenStadt, 2012a; DEFRA, 2015; Gulliver et al., 2015). This also seems to be the practice of many assessment approaches in which noise exposure costs are computed based on static resident numbers (see, e.g., FGSV, 1997; ITP and VWI, 2006). This makes sense for night times (see, e.g., BVU et al., 2003, pp. 187-189), whereas, during the day residents may have left their homes in order to perform other activities at different locations. Hence, the estimated noise costs or exposure analysis may lead to wrong recommendations for policy makers. Lam and Chung (2012) consider the socio-economic characteristics and find older and less educated residents in Hong Kong's private buildings to be worst affected by traffic noise. Murphy and King (2010) address the absence of a standard method for the estimation of population exposures to noise in the European Union and mention the importance of considering residents who regularly leave their home town (e.g. weekend commuters). However, the authors do not refer to residents who leave their dwelling during the day (e.g. daily commuters). Ruiz-Padillo et al. (2014) present a methodology to compute a road stretch-specific priority index to be used for action planning. This index is composed of several variables including the noise level and residential exposures. Moreover, the proposed index takes into consideration the land use, i.e. noise sensitive buildings. Tenaileau et al. (2015) discuss the definition of the considered area for the quantification of noise exposures and point out that in epidemiological research this exposure area is primarily limited to the home, i.e. the dwelling, whereas, in case outdoor exposures are considered, this area is usually extended to the relevant neighborhood. The authors conclude that noise exposures should ideally be individually evaluated to account for the differences in the daily activity and travel behavior patterns. Whereas, in context of air pollution, Hatzopoulou and Miller (2010) explicitly consider the temporal and spatial variation in air quality and population by using an activity-based demand model.

The tendency that most assessment methods and strategic noise mapping approaches are 
limited to residential exposures seems surprising as several regulations and studies also address noise in context of other activity types. Limit values which usually refer to the A-weighted and time-averaged sound level (noise assessment level), may be used for an activity-specific evaluation of noise exposures.

In Germany, limit values for traffic noise levels during the day, defined in 16. BImSchV, are differentiated according to the land use type, e.g. $57 \mathrm{~dB}(\mathrm{~A})$ for hospitals, schools, sanatoriums, retirement homes, $59 \mathrm{~dB}(\mathrm{~A})$ for residential areas, $69 \mathrm{~dB}(\mathrm{~A})$ for commercial areas. For the night, limit values are reduced by $10 \mathrm{~dB}(\mathrm{~A})$ compared to the day, which correspond to halving/doubling the perceived loudness. In contrast, for noise during night times, in WHO Europe (2009) a much lower outside noise level of $40 \mathrm{~dB}(\mathrm{~A})$ is recommended. Further activity-specific noise limits are found in context of noise protection at the workplace. In addition to noise from outside of the building (e.g. traffic noise), these regulations usually include noise sources at the workplace (e.g. machines, conversations of colleagues). Thus, provided limit values refer to the indoor sound level. An evaluation which includes the effects of annoyance and disturbance in computer workspaces describe an averaged sound level below $30 \mathrm{~dB}(\mathrm{~A})$ as the optimal working environment, 30-40 $\mathrm{dB}(\mathrm{A})$ as very good, 40-45 $\mathrm{dB}(\mathrm{A})$ as good, $45-50 \mathrm{~dB}(\mathrm{~A})$ as acceptable in a commercial environment, 50-55 dB(A) as inconvenient and noise levels above $55 \mathrm{~dB}(\mathrm{~A})$ as too high (Rau et al., 2003). DIN EN ISO 11690-1, an international standard adopted at European and national level, points in a similar direction and recommends noise limit values of $35-45 \mathrm{~dB}(\mathrm{~A})$ for mainly mental activities and 45-55 dB(A) for repetitive office work; in classrooms, background noise levels should not exceed $30-40 \mathrm{~dB}(\mathrm{~A})$. Since these values are indoor noise limits, values for the outside facade may be derived by adding a value for the insulation of the building. The level of sound reduction depends on the specific characteristics of the building (e.g. wall thickness, number and size of windows), the window technology (e.g. single vs. multiple glazing) as well as personal habits (e.g. open vs. closed windows). Numbers for the sound reduction of closed windows range from $25 \mathrm{~dB}$ to more than 48 dB (see, e.g. DIN 4109, Beiblatt 1, p. 55-56). Open windows are described to reduce the noise level by $5 \mathrm{~dB}$, partly opened windows by about $15 \mathrm{~dB}$ (see, e.g. RPS, 2011, Appendix 8). During night times, windows in bedrooms are found to be closed in $25 \%$ of the nights, and as average inside/outside differences $21.3 \mathrm{~dB}$ (single-glazed window) and $22.2 \mathrm{~dB}$ (double-glazed window) are given (WHO Europe, 2009). Hence, outside noise 
levels above $35 \mathrm{~dB}(\mathrm{~A})$ for open windows, and above $55 \mathrm{~dB}(\mathrm{~A})$ for closed windows and the worst case noise insulation, may already lead to a not optimal working environment.

To the best of the authors' knowledge, there are no studies on noise exposures which explicitly take into account the within day dynamics of varying population densities in different areas of the city and incorporate people that are affected at work, university or school. The present study takes up this lack of research and investigates for the case study of the Greater Berlin area the importance of dynamically considering various activity types.

Noise computation methods require information about the traffic situation, e.g. the flow and the share of Heavy Goods Vehicles (HGV) per spatial and temporal unit. In order to determine the exposures to noise or noise damages, information about the population is additionally required, e.g. the number of individuals and their specific activities per spatial and temporal unit. An activity-based transport model contains both, activities such as being at home, working, studying, as well as trips resulting from the need to get from one activity location to another one. Thus, activity-based transport models are well suited to obtain the required input data. In this study, an activity-based and dynamic transport simulation will be coupled with a simple noise computation model which is mainly based on the RLS-90 approach.

The paper is structured as follows. Sec. 2 provides a methodological description of the applied simulation framework as well as the noise exposure computation model. Sec. 3 describes the setup of the Berlin case study which is used for the estimation of noise exposures. The results are given and discussed in Sec. 4. Finally, Sec. 5 provides a conclusion and outlook on related future studies.

\section{Methodology}

\subsection{Transport Simulation Framework}

In this study, the activity-based open-source simulation framework MATSim ${ }^{2}$ is used for the investigation of noise exposures. The demand side is represented by individual agents that make use of the transport supply (e.g. the road network) in order to travel between

\footnotetext{
${ }^{2}$ Multi-Agent Transport Simulation, see www.matsim.org
} 
different activity locations (e.g. the home location, the workplace, a shopping activity). In a first step, initial daily travel plans are generated for each agent. These travel plans describe individual activity chains, initial activity end times and the initial transport mode for the trips in between two activities. In an evolutionary iterative approach the agents interact and adapt to the transport supply. The iterative approach enables the agents to improve and obtain plausible travel alternatives, and the simulation outcome to stabilize. Based on the assumption that the agents' travel alternatives represent valid choice sets, the system state is considered to converge towards a stochastic user equilibrium (Nagel and Flötteröd, 2012). For an in-depth description of the transport simulation framework, see e.g. Raney and Nagel (2006).

\subsection{Computation of noise damages}

The presented approach to compute road noise damages is based on a modular design which is visualized in Fig. 1. A first module computes the noise emissions based on the

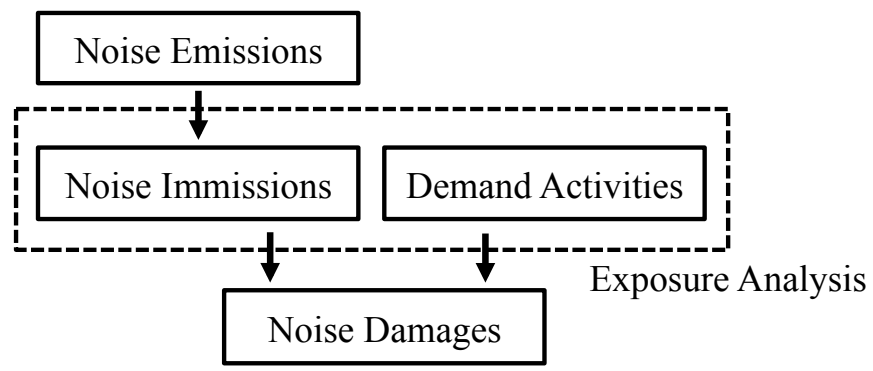

Figure 1: Modular design to calculate noise damages

traffic flow, HGV share and the speed level. Based on these emissions and additional spatial information, a second module calculates the noise immissions for a predefined set of receiver points. A third module keeps track of each individual's activity locations as well as activity start and end times. Based on the activity information as well as the noise immissions, noise exposures may be investigated, and a forth module computes individual noise damage costs. A detailed look into each module is given in the following four sections. 


\subsubsection{Noise emissions}

The calculation of noise emissions is based on the German RLS-90 approach ('Richtlinien für den Lärmschutz an Straßen', FGSV, 1992). According to this approach, in a first step, the average sound level is calculated for a predefined set of conditions, i.e. a free sound propagation along a horizontal distance of 25 meters with a height difference of 2.25 meters, a maximum speed level of $100 \mathrm{~km} / \mathrm{h}$, a smooth asphalt road surface and a gradient of less than $5 \%$. The average sound level for a single road segment and a single time bin is computed as follows.

$$
E_{i, t}^{25}=37.3+10 \cdot \log _{10}\left[M_{i, t} \cdot\left(1+0.082 \cdot p_{i, t}\right)\right]
$$

where $i$ denotes a road segment; $t$ is the time bin; $E_{i, t}^{25}$ is the average sound level in $\mathrm{dB}(\mathrm{A})$; $M_{i, t}$ is the traffic volume; and $p_{i, t}$ is the $\mathrm{HGV}$ share in \%. In a second step, $E_{i, t}^{25}$ is adjusted for deviations from the conditions in Eq. 1. The correction term for deviations from a maximum speed of $100 \mathrm{~km} / \mathrm{h}$ is calculated as follows.

$$
D_{i}^{v}=E_{i}^{c a r}-37.3+10 \cdot \log _{10}\left[\frac{100+\left(10^{0.1 \cdot\left(E_{i}^{h g v}-E_{i}^{c a r}\right)}-1\right) \cdot p}{100+8.23 \cdot p}\right]
$$

where $D_{i}^{v}$ is the speed correction, and $E_{i}^{c a r}$ and $E_{i}^{h g v}$ are calculated as described in Eq. 3 and Eq. 4.

$$
E_{i}^{c a r}=27.7+10 \cdot \log _{10}\left[1+\left(0.02 \cdot v_{i}^{c a r}\right)^{3}\right]
$$

where $v_{i}^{c a r}$ denotes the maximum speed for passenger cars.

$$
E_{i}^{h g v}=23.1+12.5 \cdot \log _{10}\left(v_{i}^{h g v}\right)
$$

where $v_{i}^{h g v}$ denotes the maximum speed for HGV. Even though the applied simulation approach provides the actual speed levels, in this study the RLS-90 approach is followed using each road's maximum speed level. In this study, for reasons of simplification and to keep the amount of input data at a low level, further corrections are assumed to be zero. In particular, the impact of a different road surface, road gradients larger than $5 \%$ and single reflections are ignored. Hence, the resulting noise emission level for a single road segment and time bin is calculated as follows.

$$
E_{i, t}=E_{i, t}^{25}+D_{i}^{v}
$$


where $E_{i, t}$ denotes the resulting average noise emission level in $\mathrm{dB}(\mathrm{A})$.

The RLS-90 approach defines a time bin size of $T=1$ hour. Therefore, even though the dynamic simulation approach allows for much smaller time bin sizes, in this study, the RLS-90 approach is followed.

\subsubsection{Noise immissions}

For a better computational performance, noise immissions are not calculated for every single activity location but instead for a grid of receiver points with a predefined density. The decrease in noise with the distance due to air absorption is calculated according to the RLS-90 approach 'lange, gerade Fahrstreifen' ('long, straight lanes'), given in Eq. 6.

$$
D_{i, j}^{d}=15.8-10 \cdot \log _{10}\left(d_{i, j}\right)-0.0142 \cdot d_{i, j}^{0.9}
$$

where $j$ denotes the receiver point; $D_{i, j}^{d}$ is the correction in $\mathrm{dB}(\mathrm{A})$; and $d_{i, j}$ is the distance between the road segment $i$ and the receiver point $j$. When calculating the distance, the shortest connection is used which is either the perpendicular or the line starting at one end of the road segment. In case the perpendicular or line distance is less than 5 meters, the distance is set to 5 meters. The length of a road segment for which noise emissions are calculated should have no impact on the noise immission level at the receiver point. Therefore, an additional correction term is introduced which is taken from Nielsen et al. (1996).

$$
D_{i, j}^{\alpha}=10 \cdot \log _{10}\left(\frac{\alpha}{180}\right)
$$

where $D_{i, j}^{\alpha}$ denotes the length (or angle) correction in $\mathrm{dB}(\mathrm{A})$; and $\alpha$ is the angle of view from receiver point $j$ to road segment $i$, as depicted in Fig. 2.

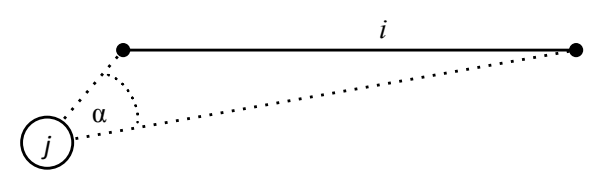

Figure 2: Correction for the length of the road segment

In this study, further corrections which take into account ground attenuation, multiple reflections or shielding of buildings are not accounted for. Hence, the noise immission 
level which results from a single road segment is calculated as follows.

$$
I_{i, j, t}=E_{i, t}+D_{i, j}^{d}+D_{i, j}^{\alpha}
$$

where $I_{i, j, t}$ denotes the noise immission level in $\mathrm{dB}(\mathrm{A})$ at receiver point $j$ resulting from road segment $i$ for the time bin $t$. If the road segment $i$ is a tunnel, the resulting noise immission level $I_{i, j, t}$ is $0 \mathrm{~dB}(\mathrm{~A})$. The superposition of average noise levels which result from several road segments is calculated applying the basic principle of energetic addition.

$$
I_{j, t}=10 \cdot \log _{10} \sum_{i} 10^{0.1 \cdot I_{i, j, t}} \quad\left\{I_{i, j, t}>0\right\}
$$

where $I_{j, t}$ is the resulting immission level in $\mathrm{dB}(\mathrm{A})$ at receiver point $j$. For a better computational performance, in this study, only the road segments within a maximum radius of 500 meters around each receiver point are taken into account, whereas the impact of road segments that are further away is neglected.

\subsubsection{Demand activities}

Applying an activity-based simulation model, individuals travel in order to get from one activity to another one. It is therefore straightforward to capture each individual's activity locations and durations throughout the day. The approach allows for different assumptions regarding which activity types are taken into account, e.g. being at home, working, performing a leisure activity. For a better computational performance, activities are considered to take place at the closest receiver point. That is, the number of individuals that may be exposed to noise is stored for each receiver point and time interval. For activities starting or ending during a time interval, the individual is partly considered, thus the number of demand units that may be exposed to noise is calculated as follows.

$$
N_{j, t}=\sum_{n} \frac{a_{n, j, t}}{T}
$$

where $N_{j, t}$ denotes number of demand units that may be exposed to noise at receiver

point $j$ in time interval $t ; n$ is the individual; $a_{n, j, t}$ is the duration individual $n$ performs an activity of a considered type (e.g. only 'home' activities; 'home' or 'work' activities) at receiver point $j$ during the time interval $t$; and $T$ is the time bin size. 


\subsubsection{Noise damages}

Analyzing the noise immissions $I_{j, t}$ with regard to the number of demand units $N_{j, t}$ for each receiver point and time interval, reveals how many individuals are affected and to which extent (exposure analysis). This module translates both parameters into one dimensions, namely the noise damage costs.

The German EWS approach ('Empfehlungen für Wirtschaftlichkeitsuntersuchungen an Straßen') suggests a threshold-based approach to calculate noise damage costs for the entire day and night. In order to compute noise damages for each time interval, the EWS method is applied to a consideration of smaller time intervals. The calculation is as follows.

$$
C_{j, t}= \begin{cases}c^{T} \cdot N_{j, t} \cdot 2^{0.1 \cdot\left(I_{j, t}-I_{t}^{\text {min }}\right)} & I_{j, t} \geq I_{t}^{\text {min }} \\ 0 & I_{j, t}<I_{t}^{\text {min }}\end{cases}
$$

where $C_{j, t}$ denotes the noise damage costs at receiver point $j$ in time interval $t$ in monetary units; $c^{T}$ is the cost rate in monetary units per $\mathrm{dB}(\mathrm{A})$ that is exposed to 1 demand unit for the duration of $T$; and $I_{t}^{\text {min }}$ is the threshold immission level which depends on the time of day. In this study, three different threshold immission levels are defined: $50 \mathrm{~dB}(\mathrm{~A})$ for time intervals during the day ( 6 a.m. to 6 p.m.), $45 \mathrm{~dB}(\mathrm{~A})$ for time intervals during the evening (6 p.m. to 10 p.m.) and $40 \mathrm{~dB}(\mathrm{~A})$ for time intervals during the night (10 p.m. to 6 a.m.). ${ }^{3}$ In this study, the annual cost rate is $c^{\text {annual }}=63.3 \mathrm{EUR}$, based on the annual cost rate of 85 DM (Deutsche Mark) given in the EWS for the year 1995, converted into EUR, and updated assuming an annual interest rate of $2 \%$. The cost rate for the predefined time interval is $c^{T}=c^{\text {annual }} \cdot \frac{T}{(365 \cdot 24)}$.

\section{Case study}

The activity-based approach to calculate noise damages is applied to a real-world scenario of the Greater Berlin area. The scenario which is used in this study was generated by Neumann et al. (2014) who converted a trip-based model into an activity-based MATSim model. The demand side is comprised of "population-representative" agents based on a SrV survey (see Ahrens, 2009) and "non-population representative" agents which account

\footnotetext{
${ }^{3}$ The EWS suggests that below an immission level of $50 \mathrm{~dB}(\mathrm{~A})$ during the day (6 a.m. to 10 p.m.), respectively $40 \mathrm{~dB}(\mathrm{~A})$ during the night (10 p.m. to 6 a.m.), the damage cost are zero.
} 
for additional traffic, such as freight, airport and tourist traffic. The model calibration was carried out taking into consideration the mode shares, travel times and distances.

The outcome is considered as the current traffic situation which is analyzed regarding the noise damages. Since this study focuses on noise caused by private road users, the traffic flow simulation only accounts for cars and HGV (heavy goods vehicles). The transport network contains all major and minor roads. Other transport modes, namely public transport, bike and walking, are modeled in a simplified way ich which trip travel times are calculated based on the beeline distance between two activity locations. Noise which is caused by public transit vehicles such as buses or streetcars, and noise resulting from other modes of transportation such as air traffic or rail transport is neglected. To improve the computational performance, the population is reduced to a sample size of $10 \%$, thus traffic volumes have to be upscaled before computing noise levels.

In this study, traffic noise exposures are investigated for two different assumptions regarding the considered activity types.

1. Damage costs are only incurred for residents who are at home. Noise which individuals are exposed to while performing another activity type is assumed not to cause any damages and is therefore neglected.

2. Noise damage costs are incurred for residents being at home, and in addition, for individuals who are exposed to noise while being at work or their place of education such as kindergarten, school or university.

\section{Results and discussion}

\subsection{Noise immissions}

At first, the investigation focuses on the noise immissions calculated for each receiver point and each time bin (see Sec. 2.2.2). Overall, the spatial plots for the Greater Berlin area seem plausible. In Fig. 3 the noise immissions are shown for a time bin during the morning peak (Fig. 3a), and for a time bin during the evening off-peak period (Fig. 3b). Since higher traffic volumes directly translate into higher noise levels, the overall noise immissions are higher during peak times. For both time periods, due to higher speed 
levels and larger traffic volumes, a higher noise immission level is observed along major roads, in particular along motorways, e.g. the inner-city southwestern motorway corridor (A115), the the inner-city motorway ring road (A100), the outer-city ring road (A10). Outside of the city boundaries (depicted in black) the speed limit is higher compared to the city region. Therefore, along several roads, the noise immissions are observed to increase outside of the city region. In the city center area, noise immissions are very high for a large number of receiver points due to the higher density of major roads and superposition effects.

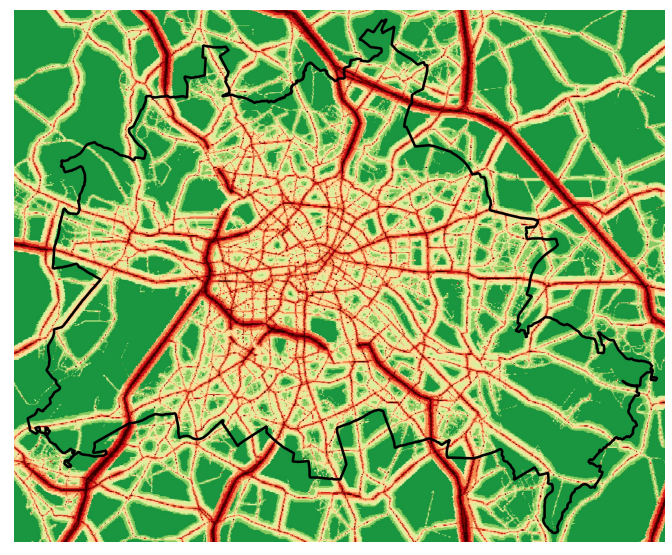

(a) peak time (7.00 - 8.00 a.m.)

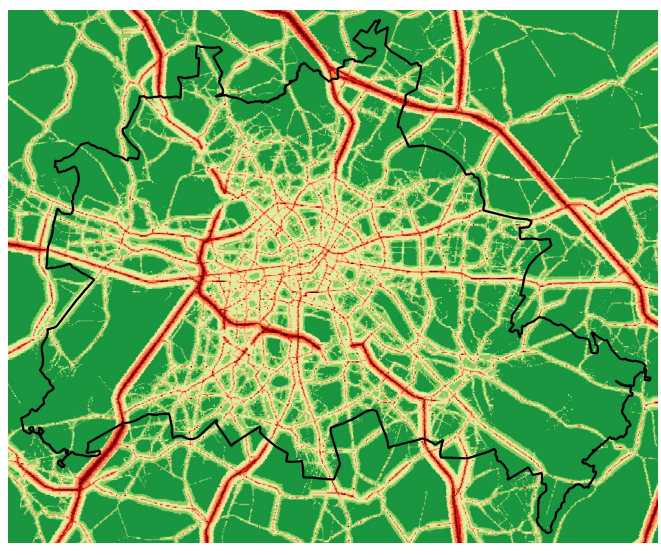

(b) off-peak time (9.00 - 10.00 p.m.)

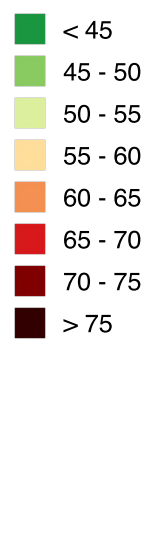

Figure 3: Temporal comparison of noise immission levels in $\mathrm{dB}(\mathrm{A})$.

Noise maps such as depicted in Fig. 3, or more common, an average noise level which accounts for the entire day, evening and night, are an important first step towards policy making. However, this illustration neglects the population that is exposed to the depicted noise levels. That is, policy makers will not be enabled to identify areas with an urgent need for action.

\subsection{Considered agent units}

To provide policy makers with further insights which may also be used to develop noise control measures, the following investigation explicitly accounts for the population, i.e. which parts of the population are affected by noise and to which extent.

Conceptually, this is done by an overlay of noise immissions and considered agent units for each receiver point and time bin. The number of agent units change during the day, and 
is calculated based on the number of agents that perform an activity of a considered type during the current time interval (see Sec. 2.2.3). Fig. 4 depicts the number of considered agent units between 10.00 and 11.00 a.m. for the two assumptions regarding the considered activity types (left-hand side: home; right-hand side: home, work, education). The

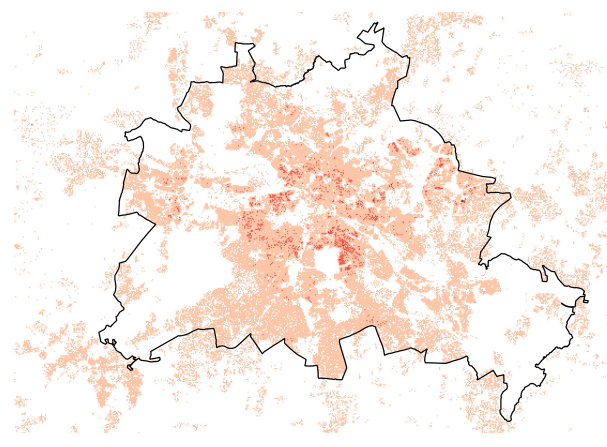

(a) home activities

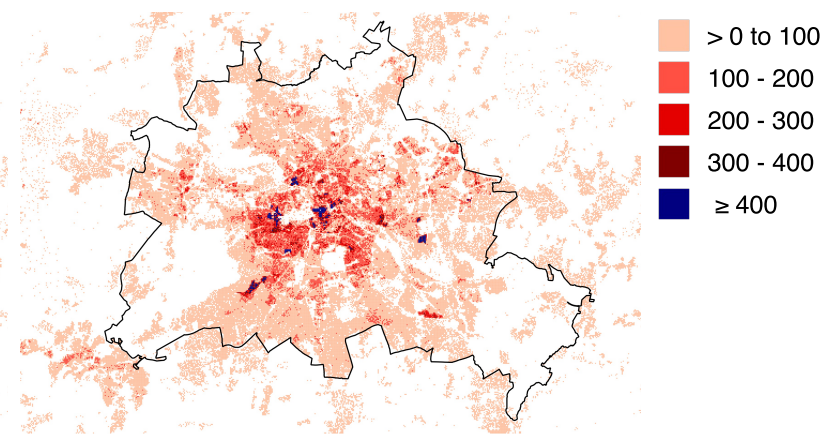

(b) home, work and education activities

Figure 4: Considered agent units between 10.00 and 11.00 a.m. for different assumptions regarding the considered activity types.

inclusion of more activity types, significantly increases the number of considered agent units that may be exposed to noise, especially in the city center where many work and education activities are concentrated in small areas. This is also observed for other times during the day. However, during the evening and night, the number of considered agent units that may be exposed to noise is about the same for both assumptions, since the majority of the population is at home.

\subsection{Exposure analysis}

At first, noise immissions that are exposed to individuals who perform work or education activities are neglected. That is, the analysis focuses on "home" as the only considered activity type where people may be affected by noise. Fig. 5 depicts the noise immissions between 10.00 and 11.00 a.m. for receiver points with different levels of affected agent units. In Fig. 5a, the noise immissions are displayed for all receiver points. Whereas, in Fig. 5c, for receiver points with 0 affected agent units, the noise immissions are faded out, and Fig. 5c only depicts the receiver points with more than 50 affected agent units. This illustration reveals that along most parts of the motorway, the population density between 10.00 and 11.00 a.m. is on a relative low level, i.e. along the motorways outside of the 


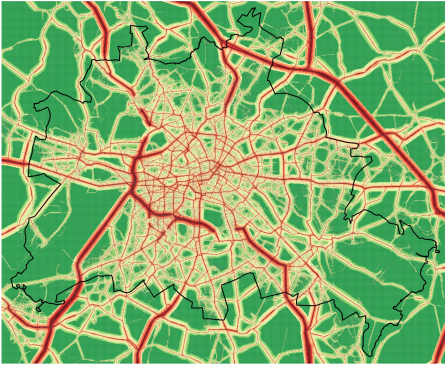

(a) all receiver points

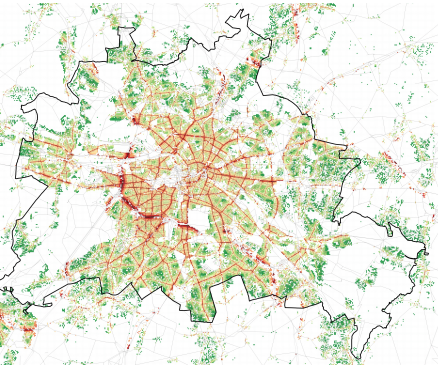

(b) $>0$ affected agent units

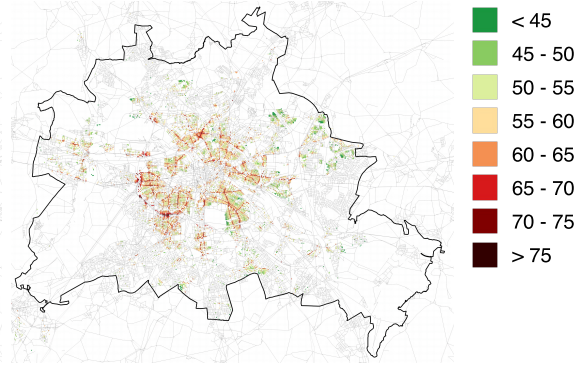

(c) $>50$ affected agent units

Figure 5: Noise immissions in $\mathrm{dB}(\mathrm{A})$ for different levels of affected agents between 10.00 and 11.00 a.m. (considered activity type: home).

city center, which results in relatively small numbers of affected agents in these areas. However, for certain areas, mainly in the city center area, the noise level is high and the number of affected agent units is relatively large. For that reason, in the following, the city center area is investigated in more detail.

Fig. 6 compares the noise immissions of the inner-city area of Berlin which are exposed to individuals who perform a "home" activity during the day (10.00 - 11.00 a.m., Fig. 6a) and in the evening (9.00 - 10.00 p.m., Fig. 6b). Noise immissions which do not affect any agent unit are faded out. For receiver points with less than 75 affected agent units, the transparency is set to $75 \%$. It becomes apparent, that the within-day dynamics of the

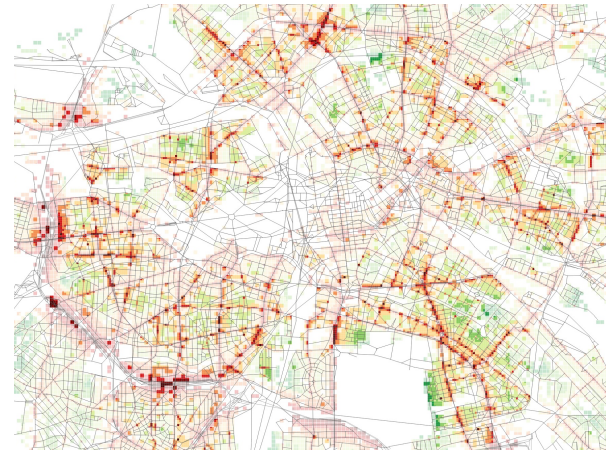

(a) 10.00 to 11.00 a.m.

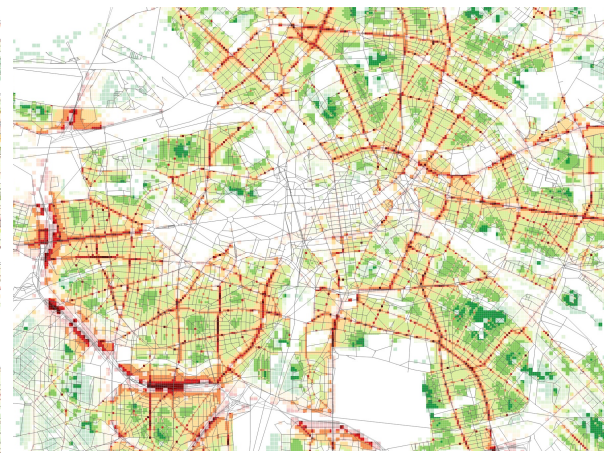

(b) 9.00 to 10.00 p.m.

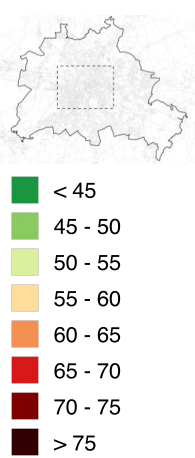

Figure 6: Temporal comparison of the most relevant inner-city noise immissions in $\mathrm{dB}(\mathrm{A})$; considered activity type: home; receiver points with 0 affected agent units are not displayed; for receiver points with less than 75 affected agent units, the transparency is set to $75 \%$.

population density have a significant impact on the overall noise exposures. During the day, less individuals are at home, and since further activity types are neglected, the number 
of affected agents is very small (Fig. 6a). Whereas, in the evening, most individuals are at home and the number of considered agent units that are exposed to noise is much larger (Fig. 6b). Along most parts of the inner-city motorway, the population density is relatively small. Therefore, in these areas, traffic noise does not cause substantial damage. However, in some areas, the noise level is high and the number of affected agent units is relatively large. During the day, mainly at the southern and western part of the inner-city motorway ring road (A100), as well as along major corridors heading from the A100 and the northeastern area of Berlin towards the city center. In the evening, high noise levels and large numbers of affected agents are found in further areas along the southwestern part of the A100, as well as along main roads inside and outside the city center area.

Next, in addition to the activity type "home", also "work" and "education" activities are assumed to be relevant and will therefore be considered in the calculation of affected agent units. Fig. 7 shows the noise immissions for areas with a large number of affected agent units in the time interval from 10.00 until 11.00 a.m. Again, receiver points with 0 affected agent units are not displayed. Since the absolute number of agent units is much larger compared to Fig. 6, and in order to point out the most relevant noise immissions, for receiver points with less than 200 affected agent units, the transparency is set to $75 \%$. A comparison of Fig. 7 and Fig 6a reveals a substantial change in the results. In the

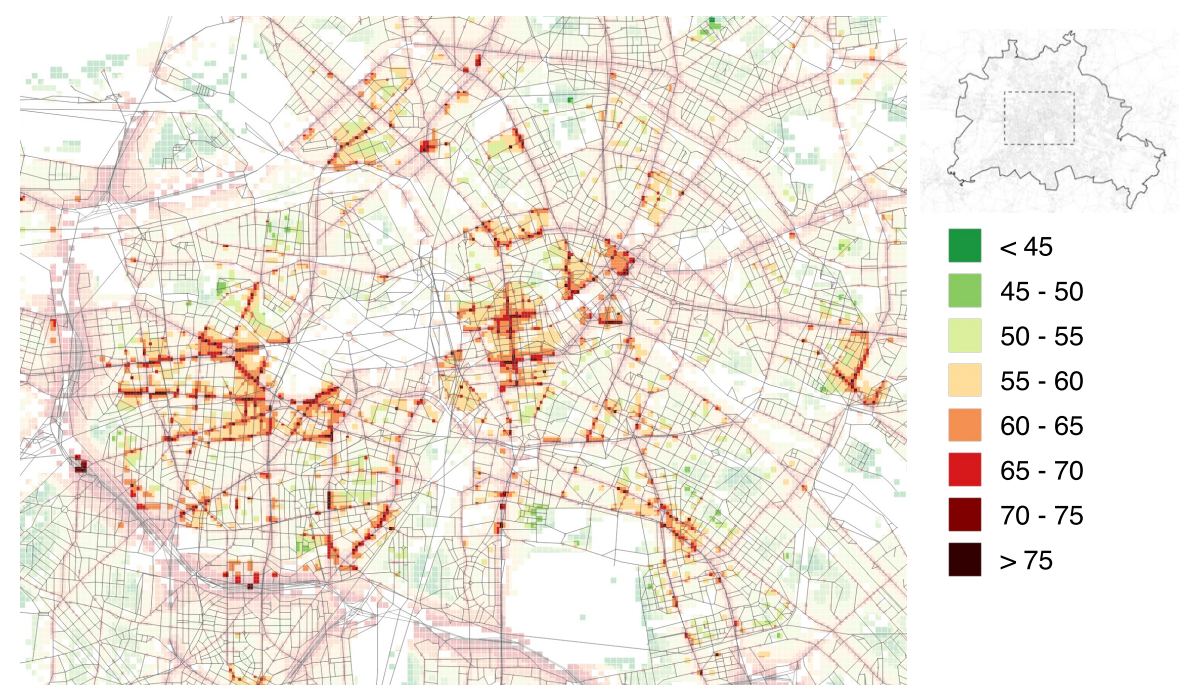

Figure 7: Most relevant inner-city noise immissions in dB(A) between 10.00 and 11.00 a.m.; considered activity types: home, work, education; receiver points with 0 affected agent units are not displayed; for receiver points with less than 200 affected agent units, the transparency is set to $75 \%$. 
previous consideration, the most affected population is identified along parts of the innercity motorway ring-road (A100) as well as in residential areas at the inner-city side of the ring-road (see Fig 6a). Whereas, now, high noise levels and many affected individuals are identified in the western business district and university campus in Berlin-Charlottenburg (e.g. Kurfürstendamm, Kantstraße, Ernst-Reuter-Platz) and the eastern business district and university campus in Berlin-Mitte (e.g. Friedrichstraße, Unter den Linden).

\subsection{Noise damages}

Next, the noise level and the number of affected agent units are transferred into one dimension, namely the damage costs (see Sec. 2.2.4). The total damages per day amount to 812,591 EUR considering home activities only. Including work and education activities increases the total damage costs by 255,523 EUR (total damage costs: 1,068,114 EUR). Thus, the average noise damage while being at home amounts to 0.18 EUR, and respectively to 0.24 EUR while being at home and at work, university, school or kindergarten. As described in Sec. 4.2, the difference between the two assumptions regarding the considered activity types, is most significant during the day. Fig. 8 depicts the noise damage cost in 1000 EUR per time of day for both assumptions regarding the considered activity types (blue: home; red: home, work, education). The fluctuations of the noise damages

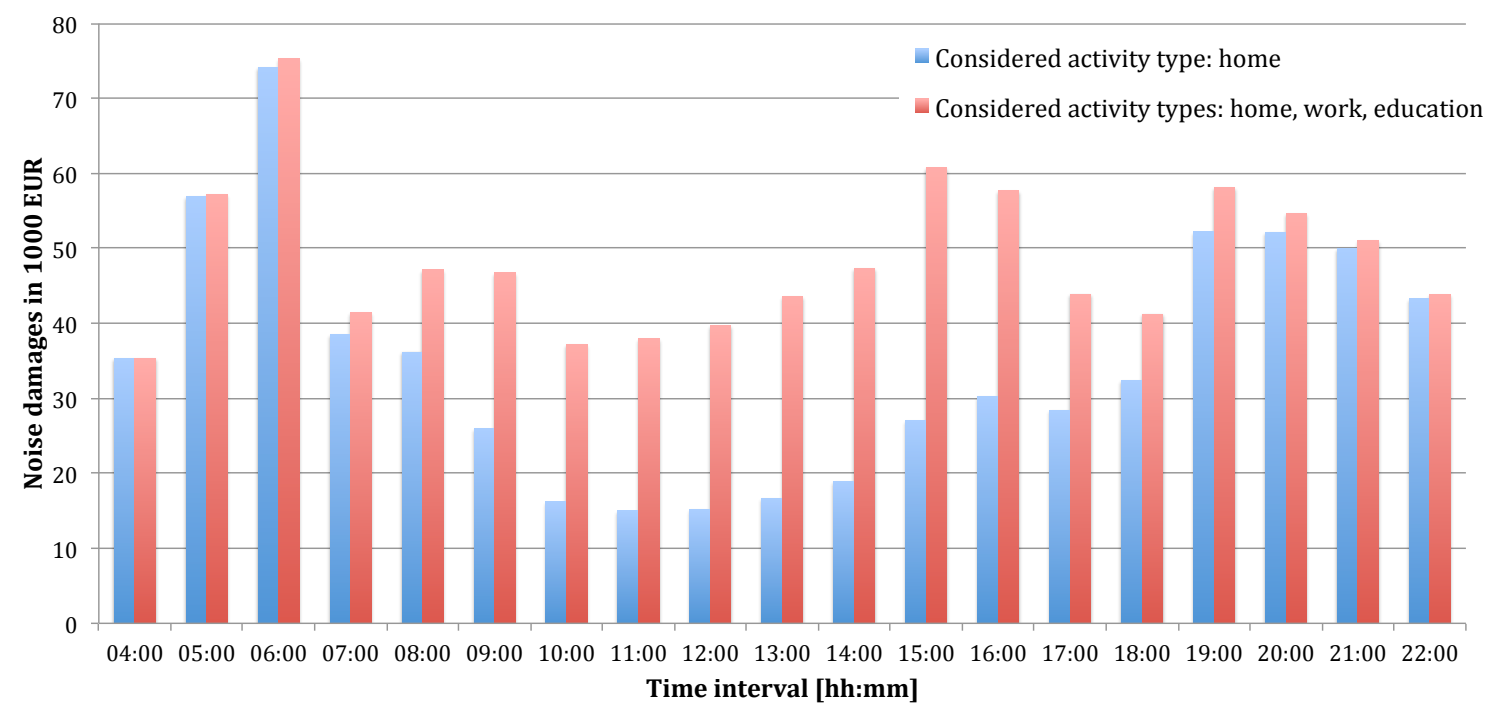

Figure 8: Noise damages in 1000 EUR per time bin (end time) for both assumptions regarding the considered activity types. 
per time exhibit several peaks which are the result of an overlay of (i) changes in the noise immissions due to a varying traffic volumes, (ii) changing numbers of affected agents and (iii) different threshold values depending on the time of day. The peaks at around 08.00 a.m. and 3.00 p.m. correspond to the higher noise levels during the morning and afternoon rush-hour. Between 06.00 a.m. and 6.00 p.m. higher noise levels are compensated by a higher threshold value of $50 \mathrm{~dB}(\mathrm{~A})$. Whereas, in the evening and night, lower thresholds values of $45 \mathrm{~dB}(\mathrm{~A})$ and $40 \mathrm{~dB}(\mathrm{~A})$ increase the damage costs even though the noise levels are on a lower level.

\section{Conclusion}

Most noise maps do not include estimates for the people that are exposed to the computed noise levels. If exposures are taken into account, the evaluation is limited to the affected people in dwellings even though several regulations and studies indicate the importance to include further activity types such as working or being in school. Furthermore, the exposures are computed based on static resident numbers, thus neglecting spatial and temporal variations in the population. In this study, an activity-based and dynamic approach is presented to calculate road traffic noise damages and investigate population exposures. The contribution of this approach is that (1) affected people at the workplace and places of education are incorporated and (2) the within day dynamics of varying population densities in different areas of the city is explicitly taken into account. The proposed methodology is applied to a real-world case study of the Greater Berlin area.

Overall, the results seem plausible in terms of the computed noise levels as well as the number of affected individuals. The main findings of this study are summarized below.

First, it is shown that the number of affected people may be incorporated into a noise map by means of an additional layer (see e.g. Fig. 5). The overlay of noise level and number of affected people reveals that only a small number of people is exposed to the relatively high motorway noise emissions. In contrast, most of the individuals are found to be affected along major inner-city roads.

Second, the results demonstrate the need to account for the within-day dynamics of varying population densities in different areas of the city. As indicated by the temporal comparison 
(Fig. 6), in primary residential areas, less people are exposed to noise during the day compared to the evening or night. Thus, the use of static resident numbers would result in an overestimation of noise damages in residential areas during the day.

Third, the study points out that the inclusion of further activity types has a substantial effect on the results. Assuming people at the workplace, university, school or kindergarten to be additionally affected by noise, as indicated by several studies and regulations, noise exposures are very large in the central business districts. Whereas, only assuming individuals at their home location to be affected by noise, the most significant noise damages are observed in more residential areas around the central business districts.

Overall, this study may be seen as a first step towards an enhancement of exposure analysis and noise mapping standards by explicitly considering the complexities and dynamics of people's travel behavior and daily activities. Hence, a more precise exposure analysis allows to provide better recommendations for policy makers and may therefore induce a more efficient use of noise control measures.

The precision of the estimated noise exposures, i.e. the number of affected people and the noise levels, crucially depends on the quality of the underlying activity-based transport model. Therefore, the results provided in Sec. 4 have to be seen in context of the model assumptions.

As described in Sec. 2.2.1 and 2.2.2, for reasons of simplification and a better computational performance, several noise-related impacts are not accounted for, such as shielding effects of buildings, single and multiple reflections, the road surface and road gradients. Depending on the availability of data, the applied simulation approach may be extended to include additional corrections in the computation of noise emissions and immissions. However, the objective of this paper is to enhance noise mapping standards by pointing out the importance of a more sophisticated consideration of the people that may be exposed to road traffic noise. That is, the focus is placed on the exposure analysis - an essential element of strategic noise mapping which is, however, neglected or strongly simplified in most studies (see Sec. 1). The presented methodology makes use of the detailed representation of the demand side in the applied transport model (see Sec. 2.1 and 2.2.3). And in return, the computation of noise propagation and immission is simplified to a reasonable level of complexity. The fast computational performance is in particular important for 
three reasons: noise maps may be drawn for large-scale areas (an entire city including the surrounding area), noise levels may be computed for all road types (minor and major roads), and the approach may be used for internalization studies which require an iterative computation of noise levels for all receiver points.

The noise computation may also be improved by using more specific traffic data which may easily be obtained from the traffic model, such as traffic volumes for shorter time periods than 1 hour. Since this study follows the RLS-90 approach, the speed correction is based on the maximum speed level instead of the actual speed level (see Sec. 2.2.1). By using the actual speed level, the impact of traffic congestion on the noise levels would be taken into account. As a further limitation, the presented methodology neglects the indoor noise propagation, and assumes all people at the considered activity type to be exposed to the computed noise level. However, not all people may actually be affected by traffic noise, e.g. due to workplaces or bedrooms which are not located at the most exposed building facade (see, e.g. Murphy and King, 2010; Eriksson et al., 2013) or other noise sources at the activity location (e.g. a machine at the workplace or the TV at home). Also, the cost factors, which are used for the calculation of noise damages (see Sec. 2.2.4), are not differentiated according to the type of activity even though different noise limit values are given for different activities such as mental vs. repetitive activities (see Sec. 1). The next step is to use the presented methodology for mapping back the noise damages to the causing transport users (see Gerike et al., 2012). Making use of the agent-specific modeling approach, noise damage costs may be internalized applying user-specific and time-dependent road prices. In future studies, the presented noise exposure methodology will be combined with existing computation approaches for further external effects that are based on the same simulation framework (see e.g. Kaddoura (2014) for congestion and Kickhöfer and Nagel (2013) for air pollution). 


\section{References}

16. BImSchV. Verkehrlärmschutzverordnung vom 12. Juni 1990 (BGBI. I S. 1036), die durch Artikel 1 der Verordnung vom 18. Dezember 2014 (BGBI I S. 2269) geändert worden ist. 16. Verordnung zur Durchführung des Bundes-Immissionsschutzgesetzes.

2002/49/EC. Directive of the European Parliament and of the Council of 25 June 2002 relating to the assessment and management of environmental noise. Official Journal of the European Communities.

2006 No. 2238. Environmental Protection, England: The Environmental Noise (England) Regulations 2006. URL http://www.legislation.gov.uk/uksi/2006/2238/pdfs/uksi_20062238_ en.pdf.

34. BImSchV. Verordnung über die Lärmkartierung vom 6. März 2006 (BGBl. I S. 516). 34. Verordnung zur Durchführung des Bundes-Immissionsschutzgesetzes.

Ahrens, G.-A. Endbericht zur Verkehrserhebung Mobilität in Städten - SrV 2008 in Berlin. Technical report, Technische Universität Dresden, 2009. http://www. stadtentwicklung. berlin. de/verkehr/politik_planung/zahlen_fakten/download/2_SrV_endbericht_tudresden_ 2008_berlin.pdf.

Babisch, W., G. Pershagen, J. Selander, D. Houthuijs, O. Breugelmans, E. Cadum, F. VignaTaglianti, K. Katsouyanni, A. S. Haralabidis, K. Dimakopoulou, P. Sourtzi, S. Floud, and A. L. Hansell. Noise annoyance - A modifier of the association between noise level and cardiovascular health? Science of The Total Environment, 452-453:50-57, 2013. doi: 10.1016/j.scitotenv.2013. 02.034 .

BVU, IVV, and PLANCO. Bundesverkehrswegeplan 2003 - Die gesamtwirtschaftliche Bewertungsmethodik [Federal Transport Infrastructure Plan 2003 - The economic evaluation methodology]. Final report for research project FE-Nr. 96.0790/2003, Beratergruppe Verkehr+Umwelt, Ingenieurgruppe IVV, Planco Consulting GmbH, 2003. Funded by BMVBW.

DEFRA. Environmental Noise Directive: Implementation of Round 1 Noise Action Plans: Progress Report. Technical report, Department for Environment, Food and Rural Affairs, London, UK, 2014. URL http://www.gov.uk/defra.

DEFRA. Noise Mapping England. Department for Envirionment, Food and Rural Affairs, 2015. URL http://services.defra.gov.uk/wps/portal/noise/maps. Accessed 27 January 2015. 
Department of Transport. Calculation of Road Traffic Noise (CoRTN). Her Majesty's Stationery Office, London, United Kingdom, 1988. URL http://www.noiseni.co.uk/calculation_of_ road_traffic_noise.pdf.

DIN 4109, Beiblatt 1. Sound insulation in buildings; Construction examples and calculation methods [Schallschutz im Hochbau; Ausführungsbeispiele und Rechenverfahren]. Deutsches Institut für Normung e.V. 11/1989.

DIN EN ISO 11690-1. Acoustics - Recommended practice for the design of low-noise workplaces containing machinery - Part 1: Noise control strategies (ISO 11690-1:1996); German version EN ISO 11690-1:1996 [Akustik - Richtlinien für die Gestaltung lärmarmer maschinenbestückter Arbeitsstätten - Teil 1: Allgemeine Grundlagen (ISO 11690-1:1996), Deutsche Fassung EN ISO 11690-1:1996]. Deutsches Institut für Normung e.V. 02/1997.

Eriksson, C., M. Nilsson, D. Stenkvist, T. Bellander, and G. Pershagen. Residential traffic noise exposure assessment: application and evaluation of European Environmental Noise Directive maps. Journal of Exposure Science and Environmental Epidemiology, 23:531-538, 2013. doi: 10.1038/jes.2012.60.

FGSV. Richtlinien für den Lärmschutz an Straßen (RLS), Ausgabe 1990, Berichtigte Fassung. Forschungsgesellschaft für Straßen- und Verkehrswesen, 1992. URL http://www.fgsv.de.

FGSV. Empfehlungen für Wirtschaftlichkeitsuntersuchungen an Straßen (EWS). Aktualisierung der $R A S-W$ 86. Forschungsgesellschaft für Straßen- und Verkehrswesen, 1997. URL http: //www.fgsv.de.

Garg, N. and S. Maji. A Critical review of principal traffic noise models: Strategies and implications. Environmental Impact Assessment Review, 46:68 - 81, April 2014.

Gerike, R., F. Hülsmann, F. Heidegger, J. Friedemann, and T. Becker. Quantification and mapping external noise costs back to transport users - development of an integrated urban modelling approach. In Proceedings of the European Conference on Noise Control (EURONOISE), 2012.

Gulliver, J., D. Morley, D. Vienneau, F. Fabbri, M. Bell, P. Goodman, S. Beevers, D. Dajnak, F. J. Kelly, and D. Fecht. Development of an open-source road traffic noise model for exposure assessment. Environmental Modelling \& Software, 2015. doi: http://dx.doi.org/10.1016/j.envsoft. 2014.12.022.

Hatzopoulou, M. and E. J. Miller. Linking an activity-based travel demand model with traffic emission and dispersion models: Transport's contribution to air pollution in Toronto. Transportation Research Part D: Transport and Environment, 15(6):315-325, 2010. ISSN 1361-9209. doi: 10.1016/j.trd.2010.03.007. 
Ising, H., T. Günther, C. Havestedt, C. Krause, B. Markert, H. U. Melchert, G. Schoknecht, W. Thefeld, and K. W. Tietze. Lärmbeurteilung - Extra-aurale Wirkungen. Arbeitswissenschaftliche Erkenntnisse Nr. 98, Bundesanstalt für Arbeitsschutz und Arbeitsmedizin, Dortmund, 1996.

ITP and VWI. Standardisierte Bewertung [Standardized evaluation]. Final report for research project, Intraplan Consult GmbH, Verkehrswissenschaftliches Institut Stuttgart GmbH, 2006. Funded by BMVBS.

Kaddoura, I. Marginal Congestion Cost Pricing in a Multi-Agent Simulation: Investigation of the Greater Berlin Area. VSP Working Paper 14-19, TU Berlin, Transport Systems Planning and Transport Telematics, 2014. See http://www.vsp.tu-berlin.de/publications.

Kickhöfer, B. and K. Nagel. Towards High-Resolution First-Best Air Pollution Tolls. Networks and Spatial Economics, pages 1-24, 2013. doi: 10.1007/s11067-013-9204-8.

Lam, K. and Y. T. Chung. Exposure of urban populations to road traffic noise in Hong Kong. Transportation Research Part D: Transport and Environment, 17:466-472, 2012. doi: 10.1016/ j.trd.2012.05.003.

Murphy, E. and E. A. King. Strategic environmental noise mapping: Methodological issues concerning the implementation of the EU Environmental Noise Directive and their policy implications. Environment International, 36(3):290 - 298, 2010. doi: 10.1016/j.envint.2009.11.006.

Nagel, K. and G. Flötteröd. Agent-based traffic assignment: Going from trips to behavioural travelers. In Pendyala, R. and C. Bhat, editors, Travel Behaviour Research in an Evolving World - Selected papers from the 12th international conference on travel behaviour research, chapter 12, pages 261-294. International Association for Travel Behaviour Research, 2012. ISBN 978-1-105-47378-4.

Neumann, A., M. Balmer, and M. Rieser. Converting a Static Trip-Based Model Into a Dynamic Activity-Based Model to Analyze Public Transport Demand in Berlin. In Roorda, M. and E. Miller, editors, Travel Behaviour Research: Current Foundations, Future Prospects, chapter 7, pages 151-176. International Association for Travel Behaviour Research (IATBR), 02 2014. ISBN 9781304715173.

Nielsen, H. L., H. Bendtsen, J. Kielland, E. Bechmann, S. Ljunggren, C. Göransson, K. Strömmer, S.-L. Paikkala, A. Jansson, P. Tómasson, J. Kragh, H. Jonasson, U. Sandberg, S. Storheier, and J. Parmanen. Road Traffic Noise. Nordic Prediction Method. TemaNord. The Nordic Council of Ministers, 1996. 
Raney, B. and K. Nagel. An improved framework for large-scale multi-agent simulations of travel behaviour. In Rietveld, P., B. Jourquin, and K. Westin, editors, Towards better performing European Transportation Systems, pages 305-347. Routledge, London, 2006.

Rau, G., K. Roßner, and P. van den Brulle. Bildschirmarbeit - Lärmminderung in Mehrpersonenbüros. Arbeitswissenschaftliche Erkenntnisse Nr. 124, Bundesanstalt für Arbeitsschutz und Arbeitsmedizin, Dortmund, 2003. ISSN 0720-1699.

RPS. Roma to Brisbane Pipeline - Dalby Compressor Station Upgrade: Environmental Management Plan. Technical report, RPS Australia East Pty Ltd, Sonus Pty Ltd, 2011.

Rückert-John, J., I. Bormann, and R. John. Umweltbewusstsein in Deutschland 2012. Technical report, Bundesministerium für Umwelt, Naturschutz und Reaktorsicherheit, 2013. URL http: //www. umweltbundesamt.de/publikationen/umweltbewusstsein-in-deutschland-2012.

Ruiz-Padillo, A., A. J. Torija, A. Ramos-Ridao, and D. P. Ruiz. A methodology for classification by priority for action: Selecting road stretches for network noise action plans. Transportation Research Part D: Transport and Environment, 29:66-78, 2014. doi: 10.1016/j.trd.2014.04.002.

SenStadt. Environmental Atlas Berlin; Strategic Noise Maps (Edition 2012); Calculation Results / Tabular Evaluations [Umweltatlas Berlin; Strategische Lärmkarten (Ausgabe 2012) / Berechnungsergebnisse / tabellarische Auswertungen]. Senatsverwaltung für Stadtentwicklung Berlin, 2012a. URL http://www.stadtentwicklung.berlin.de/umwelt/umweltatlas/ e_tab/ta705_04-06.xls. accessed 26 January 2015.

SenStadt. Environmental Atlas Berlin; Strategic Noise Maps; Road Traffic; Noise Index LDEN [Umweltatlas Berlin; Strategische Lärmkarten; Straßenverkehr; Lärmindex LDEN]. Senatsverwaltung für Stadtentwicklung Berlin, 2012b. URL http://www.stadtentwicklung. berlin.de.

Stassen, K. R., P. Collier, and R. Torfs. Environmental burden of disease due to transportation noise in Flanders (Belgium). Transportation Research Part D: Transport and Environment, 13: 355-358, 2008. doi: 10.1016/j.trd.2008.04.003.

Tenaileau, Q. M., N. Bernard, S. Pujol, H. Houot, D. Joly, and F. Mauny. Assessing residential exposure to urban noise using environmental models: does the size of the local living neighborhood matter? Journal of Exposure Science and Environmental Epidemiology, 25:89-96, 2015. doi: $10.1038 /$ jes.2014.33.

WG-AEN. Good Practice Guide for Strategic Noise Mapping and the Production of Associated Data on Noise Exposure. Technical report, European Commission Working Group Assessment of Exposure to Noise, 2006. Position Paper, Version 2, Final Draft. 
WHO Europe. Night Noise Guidelines for Europe. Technical report, World Health Organization, 2009. URL http://www . euro.who.int/__data/assets/pdf_file/0017/43316/E92845.pdf.

WHO Europe. Burden of Disease from Environmental Noise. Quantification of Health Life Years Lost in Europe. Technical report, World Health Organisation, 2011. URL http://www.euro. who.int/__data/assets/pdf_file/0008/136466/e94888.pdf. 